\title{
Psoralen stimulates osteoblast proliferation through the activation of nuclear factor- $\kappa B$-mitogen-activated protein kinase signaling
}

\author{
FEIMENG LI ${ }^{1 *}$, QIHUO LI ${ }^{2 *}$, XIAOQING HUANG ${ }^{3}$, YUNTING WANG $^{2}$, \\ CHANA GE ${ }^{2}$, YONG $\mathrm{QI}^{4}$, WEI GUO ${ }^{2}$ and HONGTAO $\mathrm{SUN}^{4}$
}

\begin{abstract}
${ }^{1}$ Guangdong Traditional Medical and Sports Injury Rehabilitation Research Institute, Guangdong Second Provincial General Hospital, Guangzhou, Guangdong 510317; ${ }^{2}$ Fourth Department of Orthopedics, The First Affiliated Hospital of Guangzhou University of Chinese Medicine, Guangzhou, Guangdong 510006; Departments of ${ }^{3}$ Chinese Medicine and ${ }^{4}$ Orthopedics, Guangdong Second Provincial General Hospital, Guangzhou, Guangdong 510317, P.R. China
\end{abstract}

Received May 11, 2016; Accepted March 23, 2017

DOI: 10.3892/etm.2017.4771

\begin{abstract}
Osteoporosis is a systemic skeletal disease that leads to increased bone fragility and susceptibility to fracture. Approximately $50 \%$ of postmenopausal women develop osteoporosis as a result of postmenopausal estrogen deficiency. To reduce fractures related to osteoporosis in women, previous studies have focused on therapeutic strategies that aim to increase bone formation or decrease bone resorption. However, pharmacological agents that aim to improve bone fracture susceptibility exhibit side effects. Current studies are investigating natural alternatives that possess the benefits of selective estrogen receptor modulators (SERMs) without the adverse effects. Recent studies have indicated that phytoestrogen may be an ideal natural SERM for the treatment of osteoporosis. In Chinese herbal medicine, psoralen, as the predominant substance of Psoralea corylifolia, is considered to be a phytoestrogen and is used as a remedy for osteoporosis. A number of studies have demonstrated the efficacy of psoralen in bone formation. However, the pathways and underlying molecular mechanisms that participate in psoralen-induced osteoblast formation are not well understood. In the present study, hFOB1.19 cells were treated with psoralen at different concentrations $(0,5,10,15$ and $20 \mu \mathrm{M})$ for $0,24,36,48$ and $72 \mathrm{~h}$, respectively. Reverse transcription-quantitative polymerase chain reaction and western blot assays were performed to detect glucose transporter 3 (GLUT3) expression. A cell counting kit-8 assay was used to analyze cell proliferation. In addition the effects of mitogen activated protein kinase inhibitors on extracellular signal-regulated kinase (ERK),
\end{abstract}

Correspondence to: Dr Hongtao Sun, Department of Orthopedics, Guangdong Second Provincial General Hospital, 466 Xinggang Road, Guangzhou, Guangdong 510317, P.R. China

E-mail: sunhongtao2002@gmail.com

${ }^{*}$ Contributed equally

Key words: psoralen, osteoblasts, proliferation, signal pathway phosphorylated (p)-ERK, p38, p-p38, c-Jun N-terminal kinase (JNK) and p-JNK expressions and cell proliferation were measured, as was the effect of nuclear factor $(\mathrm{NF})-\kappa \mathrm{B}$ inhibitor on P65 and GLUT3 expressions and cell proliferation. The results indicated that psoralen stimulates hFOB1.19 cell proliferation in a dose-dependent manner $(\mathrm{P}<0.05)$. Phospho-ERK, p38 and JNK were markedly increased by psoralen compared with the control group $(\mathrm{P}<0.05)$, and the specific inhibitors of ERK (SCH772984), p38 (SB203580) and JNK (SP600125) reversed the stimulatory effects of psoralen on signal marker phosphorylation $(\mathrm{P}<0.05)$. The rate of psoralen-induced cell proliferation was significantly suppressed by inhibitors of ERK, JNK and p38 compared with psoralen treatment alone $(\mathrm{P}<0.05)$. In addition, psoralen stimulated osteoblast proliferation via the NF- $\kappa \mathrm{B}$ signaling pathway. Therefore, the present findings suggest that psoralen may be a potential natural alternative to SERMs in the treatment of osteoporosis and fractures.

\section{Introduction}

Osteoporosis is a systemic skeletal disease characterized by low bone mass and poor quality bone tissue, which leads to increased bone fragility and susceptibility to fracture (1). Osteoporosis is a leading chronic disease, and the fracture risk associated with osteoporosis increases exponentially with age. (2) In the current aging society, osteoporosis has become a substantial burden for healthcare services and individuals. In 2005, 17 billion dollars was required for the treatment of incident fractures in the United States, in which women accounted for $71 \%$ of fractures and $75 \%$ of costs (3). Additionally, $\sim 50 \%$ of postmenopausal women may have osteoporosis and sustain an osteoporotic fracture as a result of postmenopausal estrogen deficiency (4).

Osteoporosis treatment for women has developed over recent years. To reduce the rate of osteoporosis-related fractures in women, current therapeutics principally focus on increasing bone formation or decreasing bone resorption (5). A number of medicines also aim to restore bone loss by inducing osteoblasts to form new bone tissue (6). Bisphosphonates and related therapeutics have been demonstrated to reduce the risk 
of fractures and are currently the most widely-used agents for the treatment of osteoporosis (7). Postmenopausal women with osteoporosis may also be treated with hormone replacement therapy (HRT). Drugs including tamoxifen, raloxifene and levormeloxifene are types of HRT that target estrogen receptors (ERs) or exert direct effects on the bone to reduce fracture and breast cancer risk (8). The positive effects of raloxifene on the quality and mass of bone have been indicated in a number of preclinical studies (9-11). In a long-term study, Delmas et al (12) demonstrated that long-term treatment with raloxifene induced a significant reduction in vertebral fractures in women with osteoporosis. However, HRTs, as selective estrogen receptor modulators (SERMs), exhibit side effects, and have been associated with an increased risk of coronary heart disease, venous thromboembolic events and exacerbation of menopausal symptoms (13). It has been documented that a consistent number of women taking SERMs exhibit gynecologic symptoms, such as endometrial hyperplasia (14). Therefore, natural alternatives that exert the therapeutic effects of SERMs without the associated side effects are of current interest.

Phytoestrogen are a class of non-steroidal compounds that are of plant origin or obtained from the metabolism of precursors present in plants (15). Phytoestrogens are considered to be an ideal natural SERM and have been demonstrated to stimulate osteoblast formation in vitro $(16,17)$. In epidemiological findings, Cassidy (18) observed that natural isoflavones, as a subclass of phytoestrogens, had protective effects against the development of osteoporosis. In Chinese herbal medicine, psoralen, as the primary substance of Psoralea corylifolia, has been identified as a phytoestrogen and is used as a remedy for osteoporosis (19). Several studies have demonstrated the stimulatory effects of psoralen in bone formation. For instance, Miura et al (20) observed that crude fractions of $P$. corylifolia seeds stimulated rat bone calcification and increased bone quality in vivo. In vitro, the crude ethanol extract of $P$. corylifolia stimulated osteoblast-like differentiation of the UMR-106 osteosarcoma cells (21). Furthermore, Wong and Rabie (22) documented that psoralen was able to promote local novel bone formation in vivo. However, the pathways and underlying molecular mechanisms that participate in osteoblast formation are not well understood. In the present study, human fetal osteoblastic 1.19 (hFOB1.19) cells were treated with psoralen in vitro to identify the function of psoralen on osteoblasts and the signaling pathways involved.

\section{Materials and methods}

hFOB1.19 cell culture and treatment. hFOB1.19 cells purchased from American Type Culture Collection (Manassas, VA, USA) were cultured as described previously (23). Briefly, $1 \times 10^{5}$ cells were plated into 96 -well plate and incubated in medium composed of 1:1 Dulbecco's Modified Eagle's Medium (DMEM; Sigma-Aldrich; Merck KGaA, Darmstadt, Germany) and Ham's F12 (Gibco; Thermo Fisher Scientific Inc., Waltham, MA, USA) supplemented with $0.3 \mathrm{mg} / \mathrm{ml}$ geneticin (EMD Millipore, Billerica, MA, USA) and 10\% fetal bovine serum (FBS, Atlas Biologicals, Fort Collins, CO, USA) in a humidified atmosphere containing $5 \% \mathrm{CO}_{2}$ at $37^{\circ} \mathrm{C}$ for $24 \mathrm{~h}$. Different concentrations of psoralen $(0,5,10,15$ and
$20 \mu \mathrm{M}$; Sigma-Aldrich; P8399) were used for a cell proliferation assay. For time course assays, $1 \times 10^{5}$ cells were seeded into 96-well plate in 1:1 DMEM/Ham's F12 with $0.3 \mathrm{mg} / \mathrm{ml}$ geneticin and $10 \% \mathrm{FBS}$ at $37^{\circ} \mathrm{C}$. Cells were treated with PBS (control group) or $15 \mu \mathrm{M}$ psoralen for $0,24,36,48$ and $72 \mathrm{~h}$ at $37^{\circ} \mathrm{C}$ in a humidified atmosphere containing $5 \% \mathrm{CO}_{2}$. In mitogen-activated protein kinase (MAPK) signaling analysis, cells $\left(1 \times 10^{5}\right)$ were seeded into 6-well plates in 1:1 DMEM/Ham's F12 with $0.3 \mathrm{mg} / \mathrm{ml}$ geneticin and $10 \% \mathrm{FBS}$ at $37^{\circ} \mathrm{C}$. Cells were treated with the working concentration $10 \mu \mathrm{M}$ p38 inhibitor (SB203580) for $30 \mathrm{~min}, 10 \mu \mathrm{M}$ ERK inhibitor (SCH772984) for $16 \mathrm{~h}, 5 \mu \mathrm{M}$ JNK inhibitor (SP600125) for $12 \mathrm{~h}$ or $5 \mu \mathrm{M}$ nuclear factor (NF)- $\kappa \mathrm{B}$ inhibitor (PDTC; all from Sigma-Aldrich; Merck KGaA) for $12 \mathrm{~h}$ in DMEM: Ham's F12 medium.

Cell counting kit-8 (CCK-8) assay. A CCK-8 assay was performed to determine the effects of psoralen on hFOB1.19 cell proliferation, according to the manufacturer's instructions. Briefly, hFOB1.19 cells $\left(2 \times 10^{3}\right.$ cells/well $)$ were seeded in 96-well plates in the medium composed of 1:1 DMEM and Ham's F12 supplemented with $0.3 \mathrm{mg} / \mathrm{ml}$ geneticin and $10 \%$ FBS in a humidified atmosphere containing $5 \% \mathrm{CO}_{2}$ at $37^{\circ} \mathrm{C}$. Cells were treated with different concentrations of psoralen $(0$, $5,10,15$ and $20 \mu \mathrm{M}$ ) for $36 \mathrm{~h}$, The same amount of medium served as the control group. Cells were washed with cold phosphate buffered saline (PBS), and $10 \mu \mathrm{l}$ cell counting kit-8 (CCK-8: WST-8 Dojindo Molecular Technologies, Inc., Rockville, MD, USA) was added to each well and incubated for $2 \mathrm{~h}$ at $37^{\circ} \mathrm{C}$. Absorbance was measured at $450 \mathrm{~nm}$ using a microplate reader.

Reverse transcription-quantitative polymerase chain reaction (RT-qPCR). TRIzol reagent (Invitrogen; Thermo Fisher Scientific, Inc.) was used to extract total RNA from hFOB1.19 cells from the proliferation assay, time course assay and MAPK signaling assay groups. cDNA was acquired using a Revert Aid First Strand cDNA Synthesis kit (Thermo Fisher Scientific Inc.). The thermocycling conditions were $25^{\circ} \mathrm{C}$ for $5 \mathrm{~min}, 42^{\circ} \mathrm{C}$ for $60 \mathrm{~min}$ and $70^{\circ} \mathrm{C}$ for $10 \mathrm{mins}$. qPCR was performed using an ABI PRISM 7500 Real-Time PCR system with SYBR Premix Ex TaqTM (Takara Biotechnology Co., Ltd., Dalian, China). Thermocycling conditions were as follows: $95^{\circ} \mathrm{C}$ for $30 \mathrm{sec}$ followed by 40 cycles of $95^{\circ} \mathrm{C}$ for $5 \mathrm{sec}$ and $60^{\circ} \mathrm{C}$ for $34 \mathrm{sec}$. The glucose transporter 3 (GLUT3) gene, which is closely related to cell proliferation, was amplified with the following specific primers: Forward, 5'-CGGCTT CCTCATTACCTTC-3' and reverse, 5'-GGCACGACTTAG ACATTGG-3', as described previously (24). For, amplification of GAPDH, which was used as a stably expressed internal control (25), the following primers were used: Forward 5'-TGC CAAATATGATGACATCAAGAA-3' and reverse, 5'-GGA GTGGGTGTCGCTGTTG-3'. The relative levels of mRNA expression were calculated using the $2^{-\Delta \Delta \mathrm{Cq}}$ method normalized to GAPDH (26). All experiments were repeated three times.

Western blotting. Cells from the control group (treatment with equivalent PBS) and treatment group were lysed with radioimmunoprecipitation assay buffer (Sigma-Aldrich; Merck KGaA), according to the manufacturer's instructions. A bicinchoninic 
acid assay kit was used for the detection of protein concentrations. Proteins $(40 \mu \mathrm{g})$ were separated by $10 \%$ SDS-PAGE and transferred to $0.2-\mu \mathrm{m}$ nitrocellulose membranes using a Semi-Dry Blotting system (Bio-Rad Laboratories, Inc., Hercules, CA, USA). Membranes were blocked with 5\% skim milk for $2 \mathrm{~h}$ at room temperature and incubated with respective primary antibodies at $4^{\circ} \mathrm{C}$ overnight. The membranes were subsequently washed using TBST (Tris-Buffered Saline and Tween-20), and incubated with horseradish peroxidase labeled secondary anti-mouse or anti-rabbit IgG antibodies (1:1,000, anti-mouse, cat. no. SC-2005; 1:1,000, anti-rabbit, cat. no. SC-2004; both from Santa Cruz Biotechnology, Dallas, TX, USA) at room temperature for $2 \mathrm{~h}$. Blots were washed again with TBST and visualized using an enhanced chemiluminescence substrate kit (GE Healthcare Life Sciences, Little Chalfont, UK) and an LAS 4000 mini luminescent image analyzer (LAS-4000 mini; Fuji Film, Tokyo, Japan). GAPDH was used as a loading control. The related primary antibodies were anti-GAPDH $(1: 2,000 ;$ sc-35448-PR; Santa Cruz Biotechnology), anti-p65 (1:1,000; cat. no. ab76026; Abcam, Cambridge,UK), anti-ERK (1:2,000; cat. no. ab36991; Abcam), anti-p-ERK (1:500; cat. no. ab76165; Abcam), anti-GLUT3 (1:1,000; cat. no. ab41525; Abcam), anti-p38 (1:1,000; cat. no. ab31828 Abcam), anti-p-p38 (1:1,000; cat. no. 9215; Cell Signalling Technology, Inc., Danvers, MA, USA) anti-JNK (1:1,000; cat. no. ab7949; Abcam), anti-p-JNK (1:1,000; cat. no. ab124956 Abcam).

Statistical analysis. Statistical significance was analyzed using GraphPad Prism Software v. 6.0 (GraphPad Software, La Jolla, CA, USA) and the SPSS 20.0 software (IBM Corp., Armonk, NY, USA). All data are shown as means \pm standard deviation. $\mathrm{P}<0.05$ was considered to indicate a statistically significant difference.

\section{Results}

Psoralen stimulates $h F O B 1.19$ cell proliferation in a dose-dependent manner. hFOB1.19 cells, which exhibit only minor chromosomal translocations, are conditionally immortalized human osteoblasts (27), and serve as an ideal system in the study of osteoblasts in vitro. In the present study, the toxicity of psoralen in hFOB1.19 cells was determined. RT-qPCR analysis indicated that the level of GLUT3mRNA expression was significantly increased in hFOB1.19 cells treated with psoralen $(0,5$, 10 , and $15 \mu \mathrm{M}$ ) in a dose dependent manner. The expression level of GLUT3 was significantly increased in pthe $10 \mu \mathrm{M}$ psoralen treatment group compared with thr $5 \mu \mathrm{M}$ psoralen treatment group $(\mathrm{P}<0.01)$. Treatment with $15 \mu \mathrm{M}$ psoralen lead to a peak in the levels of GLUT3 expression in hFOB1.19 cells $\left({ }^{*} \mathrm{P}<0.05\right.$ vs. $0 \mu \mathrm{M}$; Fig. 1A). Furthermore, western blot analysis indicated that levels of GLUT3 protein expression markedly increased in a dose-dependent manner between 5-15 $\mu \mathrm{M}$ psoralen, while $20 \mu \mathrm{M}$ psoralen notably reduced levels of GLUT3 when compared with the $15 \mu \mathrm{M}$ treatment group (Fig. 1B). Collectively, these results indicated that $20 \mu \mathrm{M}$ psoralen exerted toxic effects in hFOB1.19 cells. Results of the CCK-8 assay were consistent with those of the western blot analysis, and indicated that cell proliferation was increased in a dose-dependent manner in hFOB1.19 cells up to a dose of $15 \mu \mathrm{M}$ psoralen, while treatment with $20 \mu \mathrm{M}$ psoralen markedly decreased the proliferation of cells when compared with the $15 \mu \mathrm{M}$ treatment group ( $<<0.01$ vs. $0 \mu \mathrm{M}$; Fig. 1C). As a result, $15 \mu \mathrm{M}$ psoralen was chosen as the optimal dose for subsequent experiments.

Psoralen stimulates hFOB1.19 cell proliferation in a time-dependent manner. hFOB1.19 cells treated with $15 \mu \mathrm{M}$ psoralen exhibited increased levels of GLUT3 mRNA expression in a time-dependent manner between 24-48 h; however, treatment for $72 \mathrm{~h}$ decreased the levels of GLUT3 mRNA $(\mathrm{P}<0.01$ vs. 0 h; Fig. 1D). Similar results were observed in a western blot analysis of GLUT3 protein expression (Fig. 1E). In addition, a CCK- 8 assay demonstrated that treatment with 15 $\mu \mathrm{M}$ psoralen increased cell proliferation in a time-dependent manner between $24-48 \mathrm{~h}$, while treatment for $72 \mathrm{~h}$ lead to a decrease in cell proliferation when compared to cells treated for $48 \mathrm{~h}(\mathrm{P}<0.01$ vs. $0 \mathrm{~h}$; Fig. 1F). These results indicated that $15 \mu \mathrm{M}$ psoralen for $48 \mathrm{~h}$ was the optimal treatment.

To verify the effect of psoralen on hFOB1.19 cell proliferation, $15 \mu \mathrm{M}$ psoralen was administered to hFOB1.19 cells for $48 \mathrm{~h}$. Following treatment with $15 \mu \mathrm{M}$ psoralen for $48 \mathrm{~h}$, levels of GLUT3 mRNA were significantly increased in the psoralen treatment group compared to untreated controls $(\mathrm{P}=0.002641$; Fig. 2A). Similar alterations in the levels of GLUT3 protein expression were observed by western blot analysis (Fig. 2B). Furthermore, treatment with $15 \mu \mathrm{M}$ psoralen significantly promoted the proliferation of hFOB1.19 cells between 24-72 $\mathrm{h}$ compared with the control group $(\mathrm{P}<0.05$; Fig. $2 \mathrm{C})$.

hFOB1.19 cell proliferation depends on $N K-\kappa B-M A P K$ signaling. MAPK signaling pathways have been demonstrated to participate in osteoblast proliferation (28). Previous studies have demonstrated the effect of psoralen on osteoblast proliferation in vitro $(29,30)$. To elucidate the mechanism of action of psoralen on osteoblast proliferation, the effects of psoralen on three primary signaling pathways, namely extracellular signal-related kinase (ERK), c-Jun N-terminal kinase (JNK) and MAPK, were determined by evaluating signal pathway activity and cell proliferation (Fig. 3). As depicted in Fig. 3A, after treatment with $15 \mu \mathrm{M}$ psoralen for $48 \mathrm{~h}$, levels of activated phospho-ERK and p65 were markedly increased compared with the control group. Analysis of p38 and JNK exhibited similar results (Fig. 3B and D, respectively). To verify whether MAPKs were involved in cell proliferation, hFOB 1.19 cells were treated with psoralen and inhibitors of p38, ERK, $\mathrm{JNK}$ or NF- $\mathrm{NB}$ and the effects on signaling activity and cell proliferation were evaluated. As depicted in Fig. 3A, B and D, treatment with specific inhibitors of ERK (SCH772984), p38 (SB203580) and JNK (SP600125) reversed the stimulatory effects of psoralen on signal marker phosphorylation. In addition, the rate of psoralen-induced cell proliferation was significantly suppressed by inhibitors of ERK $(\mathrm{P}=0.004676)$, JNK $(\mathrm{P}=0.001535)$ and $\mathrm{p} 38(\mathrm{P}=0.001828)$ compared with psoralen treatment alone. Results also indicated that $15 \mu \mathrm{M}$ psoralen stimulated osteoblast proliferation through the $\mathrm{NF}-\kappa \mathrm{B}$ signaling pathway. Notably, western blotting indicated that the expression of P65, as an NF- $\kappa \mathrm{B}$ signal marker (31), similar to the activities of ERK and JNK following treatment with psoralen and signaling inhibitors (Fig. 3A and D). Thus, it was suspected that the NF- $\kappa \mathrm{B}$ pathway may be involved. 

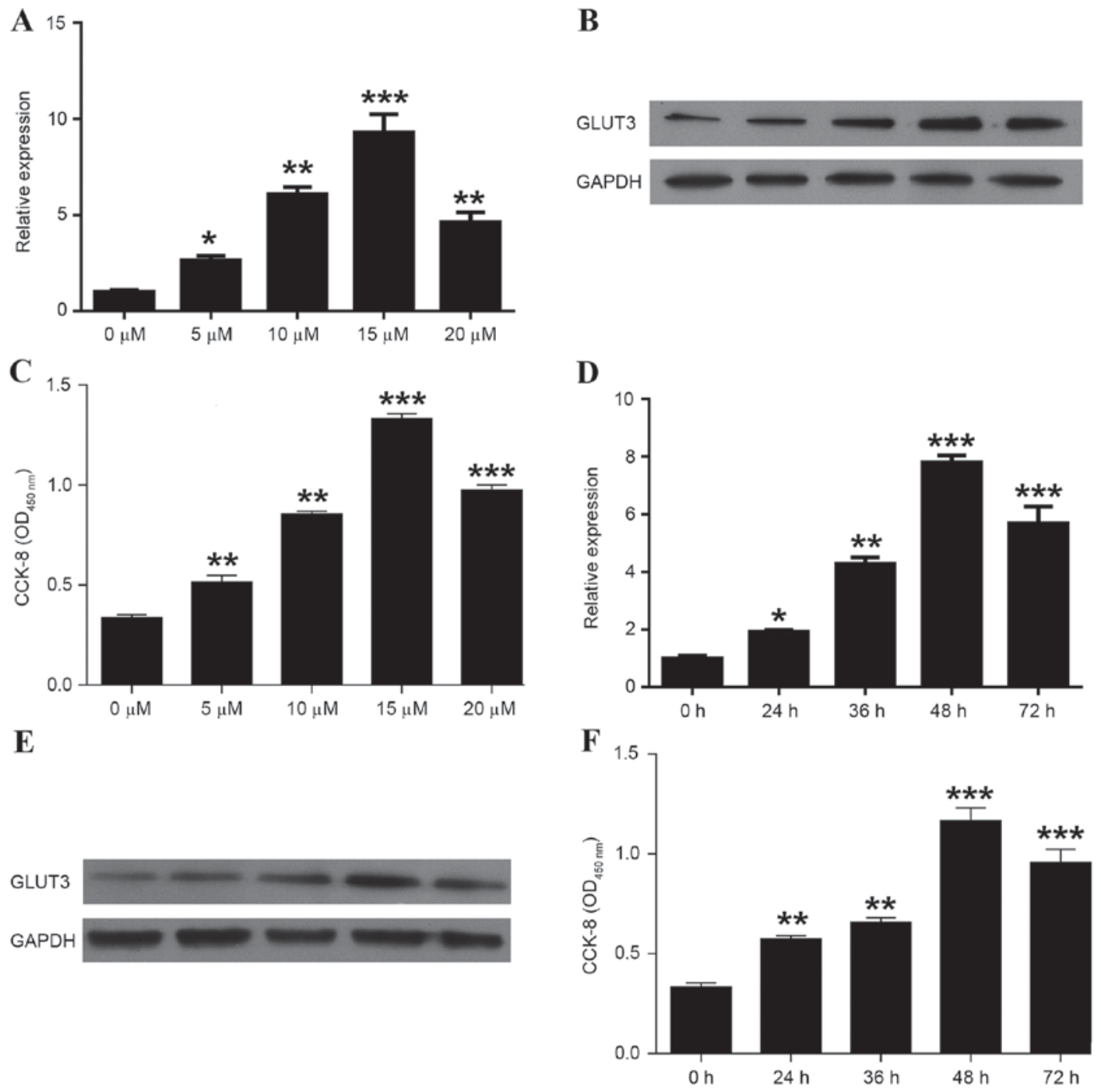

Figure 1. Time and dose-dependent effects of psoralen on hFOB1.19 cell proliferation. (A) RT-qPCR and (B) western blot analysis of GLUT3 expression at the mRNA and protein levels, respectively, in hFOB1.19 cells at psoralen concentrations of $0,5,10,15$ and $20 \mu \mathrm{M}$. GAPDH was used as a control ${ }^{*} \mathrm{P}<0.05,{ }^{* * *} \mathrm{P}<0.01$ and ${ }^{* * * *} \mathrm{P}<0.001$ vs. $0 \mu \mathrm{M}$. (C) A CCK-8 assay of hFOB1.19 cell proliferation following treatment with $0,5,10,15$ and $20 \mu \mathrm{M}$ psoralen. ${ }^{* *} \mathrm{P}<0.01$ and ${ }^{* * * *} \mathrm{P}<0.001$ vs. $0 \mu \mathrm{M}$. (D) RT-qPCR and (E) western blot analysis of GLUT3 expression in hFOB1.19 cells treated with $15 \mu \mathrm{M}$ psoralen at $0,24,36,48$ and $72 \mathrm{~h}$. GAPDH was used as a control. ${ }^{*} \mathrm{P}<0.05,{ }^{* *} \mathrm{P}<0.01$ and ${ }^{* * *} \mathrm{P}<0.001$ vs. $0 \mathrm{~h}$. (F) A CCK-8 assay of hFOB1.19 cell proliferation at $0,24,36,48$ and $72 \mathrm{~h}$ after treatment with $15 \mu \mathrm{M}$ psoralen. ${ }^{* *} \mathrm{P}<0.01$ and ${ }^{* * *} \mathrm{P}<0.001$ vs. $0 \mathrm{~h}$. hFOB1.19, human fetal osteoblastic 1.19; RT-qPCR, reverse transcription-quantitative polymerase chain reaction; GLUT3, glucose transporter 3; CCK-8, cell counting kit-8.
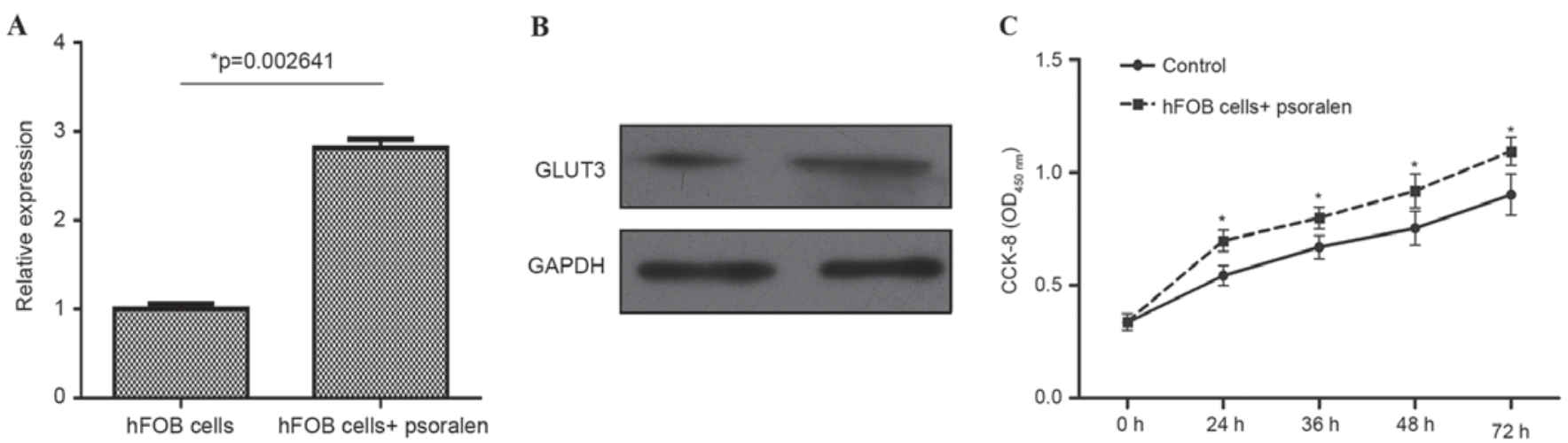

Figure 2. Effect of psoralen on hFOB1.19 cell proliferation. (A) RT-qPCR and (B) western blot analysis of GLUT3 expression at the mRNA and protein levels in hFOB1.19 cells treated with or without $15 \mu \mathrm{M}$ psoralen for $48 \mathrm{~h}$. GAPDH was used as a control. Western blotting indicated that $15 \mu \mathrm{M}$ psoralen stimulated the expression of GLUT3 protein in osteoblast cells. (C) A CCK-8 assay indicated that psoralen significantly increased cell proliferation compared with the control group at $24,36,48$, and $72 \mathrm{~h}$. ${ }^{*} \mathrm{P}<0.05$ vs. control. hFOB1.19, human fetal osteoblastic 1.19; RT-qPCR, reverse transcription-quantitative polymerase chain reaction; GLUT3, glucose transporter 3; CCK-8, cell counting kit-8. 
A

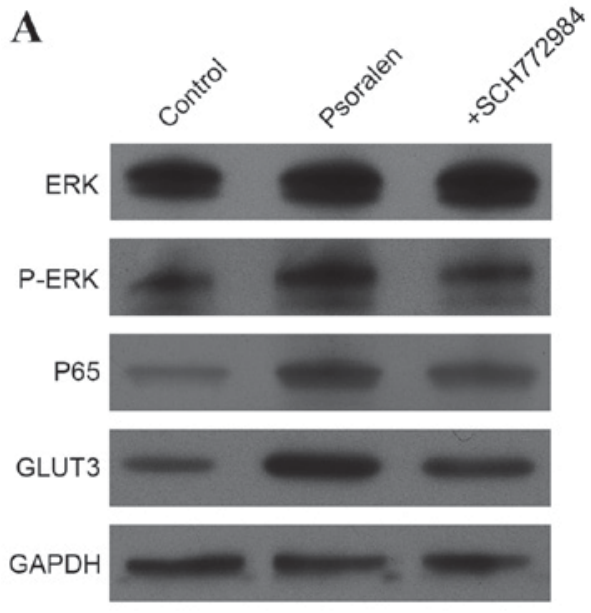

C

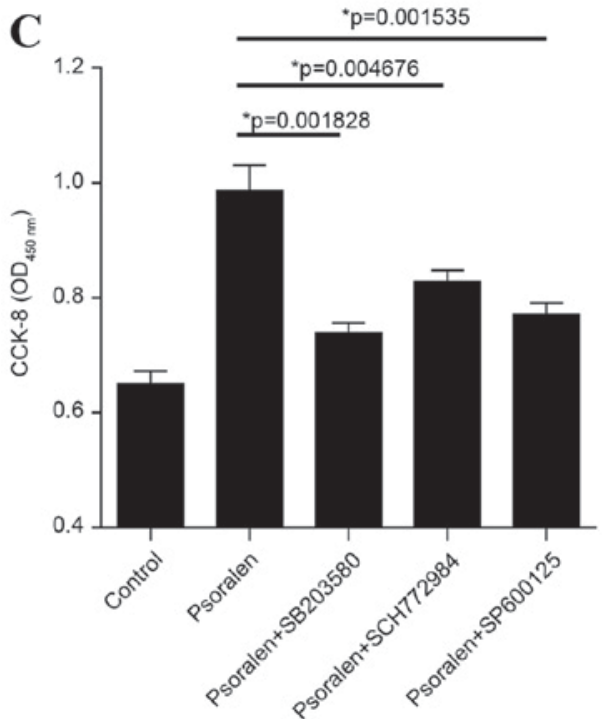

B

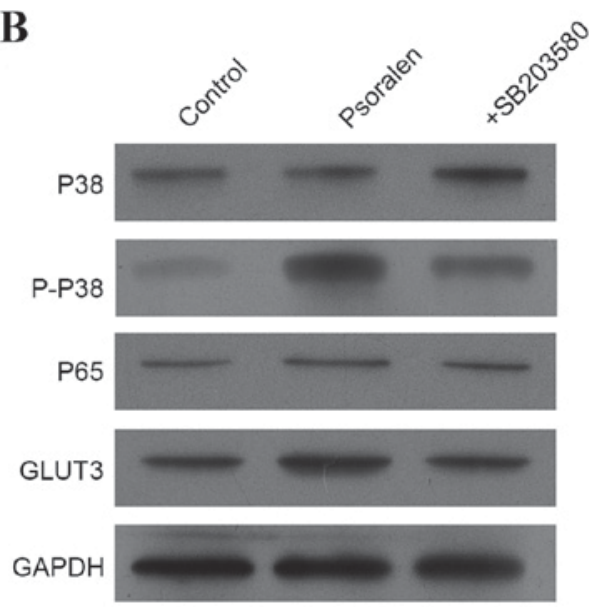

$\mathbf{D}$

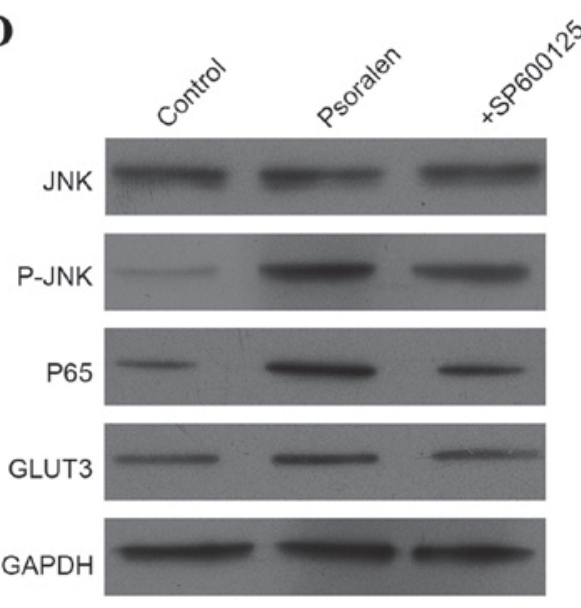

Figure 3. (A-D) Effect of MAPK inhibitors on psoralen-induced proliferation in osteoblast cells. Western blotting was used to measure the protein expression of (A) ERK, P-ERK, (B) p38, P-p38, (D) JNK and P-JNK following treatment with psoralen and MAPK inhibitors. Levels of p65, GLUT3 and GAPDH expression were also determined. GAPDH was used as a control. (C) A CCK-8 assay indicated that MAPK inhibitors significantly suppressed psoralen-induced proliferation. MAPK, mitogen-activated protein kinase; SCH772984, ERK inhibitor; SB203580, P38 inhibitor; SP600125, JNK inhibitor; ERK, extracellular signal-related kinase; JNK, c-Jun N-terminal kinase; GLUT3, glucose transporter 3; P-, phosphorylated; CCK-8, cell counting kit-8.

A

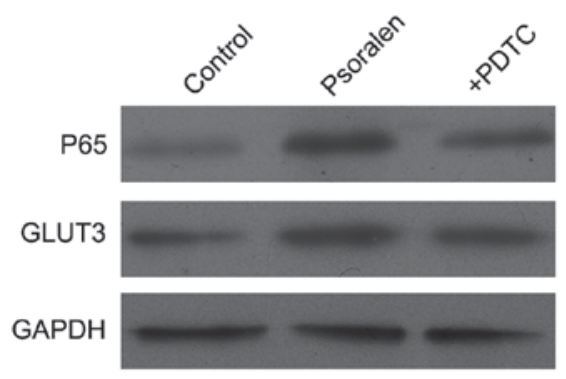

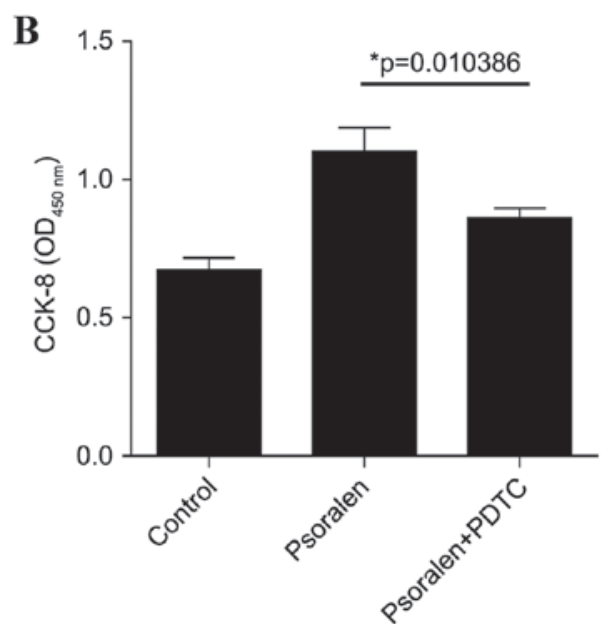

Figure 4. Effect of NF-kB inhibitor on psoralen-induced osteoblast proliferation. hFOB1.19 cells were incubated with or without PDTC in the presence or absence of $15 \mu \mathrm{M}$ psoralen. (A) Level of P65 and GLUT3 in the cell extracts were measured by western blotting. When PDTC was added, levels of P65 and GLUT3 were markedly decreased compared with the psoralen-induced group. GAPDH was used as a control. (B) A CCK-8 assay indicated that PDTC

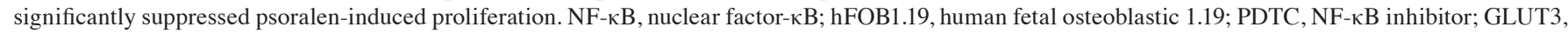
glucose transporter 3; CCK-8, cell counting kit-8. 
NF- $\kappa \mathrm{B}$ knockout mice exhibit bone disorder (32). In the majority of cells, $\mathrm{NF}-\kappa \mathrm{B}$ is present as a latent-form in the cytoplasm and stimulates the transcription of target genes in the nucleus (33). NF- $\kappa \mathrm{B}$ is involved in cellular responses to various stimuli (34). To determine whether psoralen induced $N F-\kappa B$ signaling, a NF- $\kappa$ B signal pathway inhibitor (PDTC) was administered to hFOB 1.19 cells following psoralen treatment. As depicted in Fig. 4A, cells treated with psoralen exhibited increased levels of GLUT3 and p65 compared to controls. In turn, when cells were treated with psoralen and PDTC inhibitor, the expressions of GLUT3 and p65 were reduced when compared to cells treated with psoralen alone. Furthermore, the proliferation of cells was significantly decreased when cells were treated with psoralen and PDTC inhibitor $(\mathrm{P}=0.010386$ vs. psoralen group; Fig. 4B). As similar results were obtained for $\mathrm{NF}-\kappa \mathrm{B}$ and MAPK pathway analysis, this suggested that psoralen stimulated osteoblast proliferation through NF- $\kappa$ B-MAPK signaling.

\section{Discussion}

Osteoblasts are mesenchymal cells and are responsible for bone matrix synthesis, secretion and mineralization during the bone remodeling process (35). Osteoblasts serve a key role in maintaining bone mass and reducing bone loss. During the proliferation stage, osteoblasts secrete type I collagen to aid mineralization and reduce bone loss (36). Osteoblasts also secrete osteoprotegerin, which blocks receptor activator $\mathrm{NF}-\kappa \mathrm{B}$ ligand interactions and prevents bone resorption (37).

Osteoblast proliferation is typically evaluated through measurements of total cellular protein, alkaline phosphatase activity and type I collagen secretion or GLUT3 expression (38). GLUT3 is a transporter with a high affinity for glucose and is essential for cell proliferation (39). Bell et al (40) observed that GLUT3 was expressed in osteoblasts and that glucose uptake in osteoblasts was mediated by GLUT1 and 3 .

In the present study, the mRNA and protein expression levels of GLUT3 were upregulated with increasing doses of psoralen, though cell toxicity was induced at the highest dose of $20 \mu \mathrm{M}$ psoralen. In addition, the mRNA and protein expression levels of GLUT3 were upregulated with time. Collectively, results indicated that osteoblast proliferation was increased in a dose and time-dependent manner.

Components within the MAPK, ERK and JNK signaling pathways, including insulin, glucocorticoid, hyperbaric oxygen and fibroblast growth factor-6, have been identified as major promoters of osteoblast proliferation in a number of studies (41-43). Song et al (44) demonstrated that icariin, a flavonoid glucoside isolated from $P$. corylifolia, promoted MC3T3-E1 osteoblast proliferation by inducing the activation of ERK and JNK, but exerted no effect on the activity of p38 kinase. By contrast, Luo et al (45) observed that adiponectin was able to promote osteoblast differentiation through the p38 pathway, and that adiponectin stimulated osteoblast proliferation by inducing JNK activation, but not ERK1/2, in osteoblasts. MAPK pathways serve key roles in cell proliferation, and more specifically, these pathways are considered to serve vital roles in osteoblast proliferation and differentiation (44).

A previous in vivo study indicated that bone morphogenetic proteins (BMPs) controlled osteoblast proliferation and induced bone formation (46). BMP-2 has been demonstrated to induce the activation of alkaline phosphatase genes, which serve an essential role in osteoblast differentiation (47). Kong et al (48) suggested that interactions with BMP and the MAPK signaling pathway may be involved in osteoblast proliferation.

Psoralen, as a type of furanocoumarin, is the predominant component of the leguminous plant $P$. corylifolia (49). In a recent study, psoralen has been indicated to possess bacteriostatic, anti-tumor, hemostatic and cardiovascular effects, and promote bone formation while inhibiting bone resorption (50). In addition, Tang et al (51) observed that psoralen upregulated the expression of BMP-2 to stimulate mouse calvarial osteoblast differentiation. In the present study, psoralen stimulated osteoblast proliferation through the ERK/MAPK, JNK/MAPK and p38/MAPK pathways. Furthermore, psoralen significantly increased the expression of NF- $\kappa \mathrm{B}$. This result may indicate that $\mathrm{NF}-\kappa \mathrm{B}$ was the pathway by which psoralen induced cell proliferation. Two explanations may account for these observations. First, the MAPK pathway, as an important pathway involved in the process of cell proliferation, may have stimulated osteoblasts directly. Second, psoralen-induced MAPK activation may have stimulated the BMP pathway to promote osteoblast proliferation.

In conclusion, the present findings indicated that psoralen stimulated osteoblast proliferation through the activation of $\mathrm{NF}-\kappa \mathrm{B}$ and MAPK signaling. Thus, psoralen may be a viable therapeutic agent in the treatment of osteoporosis.

\section{References}

1. Ciric Z, Stankovic I, Pejcic T, Ristic L, Rancic M and Radovic M: Osteoporosis in patients with chronic obstructive pulmonary disease. Med Arch 66: 385-387, 2012.

2. Cummings SR and LJ Melton: Epidemiology and outcomes of osteoporotic fractures. Lancet 359: 1761-17667, 2002.

3. Burge R, Dawson-Hughes B, Solomon DH, Wong JB, King A and Tosteson A: Incidence and economic burden of osteoporosis-related fractures in the United States, 2005-2025. J Bone Miner Res 22: 465-3875, 2007.

4. Maeda SS and Lazaretti-Castro M: An overview on the treatment of postmenopausal osteoporosis. Arq Bras Endocrinol Metabol 58: 162-171, 2014.

5. Zhai Y, Li Y, Wang Y, Cui J, Feng K, Kong X and Chen L: Psoralidin, a prenylated coumestan, as a novel anti-osteoporosis candidate to enhance bone formation of osteoblasts and decrease bone resorption of osteoclasts. Eur J Pharmacol 801: 62-71, 2017.

6. Baron R and Kneissel M: WNT signaling in bone homeostasis and disease: From human mutations to treatments. Nat Med 19: 179-192, 2013.

7. McClung M, Harris ST, Miller PD, Bauer DC, Davison KS, Dian L, Hanley DA, Kendler DL, Yuen CK and Lewiecki EM: Bisphosphonate therapy for osteoporosis: Benefits, risks, and drug holiday. Am J Med 126: 13-20, 2013.

8. Fitzpatrick LA: Selective estrogen receptor modulators and phytoestrogens: New therapies for the postmenopausal women. Mayo Clin Proc 74: 601-607, 1999.

9. Kimura S, Saito M, Kida Y, Seki A, Isaka Y and Marumo K: Effects of raloxifene and alendronate on non-enzymatic collagen cross-links and bone strength in ovariectomized rabbits in sequential treatments after daily human parathyroid hormone (1-34) administration. Osteoporos Int 28: 1109-1119, 2017.

10. Fujiwara S, Hamaya E, Sato M, Graham-Clarke P, Flynn JA and Burge R: Systematic review of raloxifene in postmenopausal Japanese women with osteoporosis or low bone mass (osteopenia). Clin Interv Aging 9: 1879-1893, 2014.

11. Turner $\mathrm{CH}$, Sato $\mathrm{M}$ and Bryant HU: Raloxifene preserves bone strength and bone mass in ovariectomized rats. Endocrinology 135: 2001-2005, 1994. 
12. Delmas PD, Ensrud KE, Adachi JD, Harper KD, Sarkar S, Gennari C, Reginster JY, Pols HA, Recker RR, Harris ST, et al: Efficacy of raloxifene on vertebral fracture risk reduction in postmenopausal women with osteoporosis: Four-year results from a randomized clinical trial. J Clin Endocrinol Metab 87: 3609-3617, 2002

13. Deng L, Wu T, Chen XY, Xie L and Yang J: Selective estrogen receptor modulators (SERMs) for uterine leiomyomas. Cochrane Database Syst Rev 10: CD005287, 2012.

14. Goldstein SR, Neven P, Cummings S, Colgan T, Runowicz CD, Krpan D, Proulx J, Johnson M, Thompson D, Thompson J and Sriram U: Postmenopausal Evaluation and Risk Reduction With Lasofoxifene (PEARL) trial: 5-year gynecological outcomes. Menopause 18: 17-22, 2011

15. Lóránd T, Vigh E and Garai J: Hormonal action of plant derived and anthropogenic non-steroidal estrogenic compounds: Phytoestrogens and xenoestrogens. Curr Med Chem 17: 3542-3574, 2010.

16. Choi EM, Suh KS, Kim YS, Choue RW and Koo SJ: Soybean ethanol extract increases the function of osteoblastic MC3T3-E1 cells. Phytochemistry 56: 733-739, 2001.

17. Sugimoto E and Yamaguchi M: Stimulatory effect of Daidzein in osteoblastic MC3T3-E1 cells. Biochem Pharmacol 59: 471-485, 2000

18. Cassidy A: Potential risks and benefits of phytoestrogen-rich diets. Int J Vitam Nutr Res 73: 120-126, 2003.

19. Wang L, Li Y, Guo Y, Ma R, Fu M, Niu J, Gao S and Zhang D: Herba Epimedii: An Ancient Chinese herbal medicine in the prevention and treatment of osteoporosis. Curr Pharm Des 22: 328-349, 2016

20. Miura H, Nishida H and Linuma M: Effect of crude fractions of Psoralea corylifolia seed extract on bone calcification. Planta Med 62: 150-153, 1996.

21. Xiong Z, Wang D, Xu Y and Li F: Osteoblastic differentiation bioassay and its application to investigating the activity of fractions and compounds from Psoralea corylifolia L. Pharmazie 58 925-928, 2003

22. Wong RW and Rabie AB: Effect of psoralen on bone formation J Orthop Res 29: 158-164, 2011.

23. Xiong XC, Zhu Y, Ge R, Liu LF and Yuan W: Effect of melatonin on the extracellular-regulated kinase signal pathway activation and human osteoblastic cell line hFOB 1.19 proliferation. Int J Mol Sci 16: 10337-10353, 2015.

24. Vaz CV, Alves MG, Marques R, Moreira PI, Oliveira PF, Maia CJ and Socorro S: Androgen-responsive and nonresponsive prostate cancer cells present a distinct glycolytic metabolism profile. Int J Biochem Cell Biol 44: 2077-2084, 2012

25. Aaboe M, Birkenkamp-Demtroder K, Wiuf C, Sørensen FB, Thykjaer T, Sauter G, Jensen KM, Dyrskjøt L and Ørntoft T: SOX4 expression in bladder carcinoma: Clinical aspects and in vitro functional characterization. Cancer Res 66: 3434-3442, 2006.

26. Livak KJ and TD Schmittgen: Analysis of relative gene expression data using real-time quantitative PCR and the 2(-Delta Delta C(T)) Method. Methods 25: 402-408, 2001.

27. Harris SA, Enger RJ, Riggs BL and Spelsberg TC: Development and characterization of a conditionally immortalized human fetal osteoblastic cell line. J Bone Miner Res 10: 178-186, 1995.

28. Qiao X, Nie Y, Ma Y, Chen Y, Cheng R, Yin W, Hu Y, Xu W and $\mathrm{Xu}$ L: Corrigendum: Irisin promotes osteoblast proliferation and differentiation via activating the MAP kinase signaling pathways. Sci Rep 6: 21053, 2016.

29. Li WD, Yan CP, Wu Y, Weng ZB, Yin FZ, Yang GM, Cai BC and Chen ZP: Osteoblasts proliferation and differentiation stimulating activities of the main components of Fructus Psoraleae corylifoliae. Phytomedicine 21: 400-405, 2014.

30. Chen S, Wang Y, Yang Y, Xiang T, Liu J, Zhou H and Wu X: Psoralen inhibited apoptosis of osteoporotic osteoblasts by modulating IRE1-ASK1-JNK pathway. Biomed Res Int 2017: 3524307,2017

31. Kim C and Pasparakis M: Epidermal p65/NF- $\kappa \mathrm{B}$ signalling is essential for skin carcinogenesis. EMBO Mol Med 6: 970-983, 2014.

32. Yao Z, Li Y, Yin X, Dong Y, Xing L and Boyce BF: NF-kB RelB negatively regulates osteoblast differentiation and bone formation. J Bone Miner Res 29: 866-877, 2014.
33. Iotsova V, Caamaño J, Loy J, Yang Y, Lewin A and Bravo R: Osteopetrosis in mice lacking NF-kappaB1 and NF-kappaB2. Nat Med 3: 1285-1289, 1997.

34. $\mathrm{Oh} \mathrm{H}$ and Ghosh S: NF-кB: Roles and regulation in different CD4(+) T-cell subsets. Immunol Rev 252: 41-51, 2013.

35. Muruganandan S and Sinal CJ: The impact of bone marrow adipocytes on osteoblast and osteoclast differentiation. IUBMB Life: Mar 17, 2014 (Epub ahead of print).

36. Chen W, Foo SS, Rulli NE, Taylor A, Sheng KC, Herrero LJ, Herring BL, Lidbury BA, Li RW, Walsh NC, et al: Arthritogenic alphaviral infection perturbs osteoblast function and triggers pathologic bone loss. Proc Natl Acad Sci USA 111: 6040-6045, 2014.

37. Xu T, Wang L, Tao Y, Ji Y, Deng F and Wu XH: The function of naringin in inducing secretion of osteoprotegerin and inhibiting formation of osteoclasts. Evid Based Complement Alternat Med 2016: 8981650, 2016

38. Zoidis E, Ghirlanda-Keller C and Schmid C: Stimulation of glucose transport in osteoblastic cells by parathyroid hormone and insulin-like growth factor I. Mol Cell Biochem 348: 33-42, 2011.

39. Masin M, Vazquez J, Rossi S, Groeneveld S, Samson N, Schwalie PC, Deplancke B, Frawley LE, Gouttenoire J, Moradpour D, et al: GLUT3 is induced during epithelial-mesenchymal transition and promotes tumor cell proliferation in non-small cell lung cancer. Cancer Metab 2: 11, 2014

40. Bell GI, Burant CF, Takeda J and Gould GW: Structure and function of mammalian facilitative sugar transporters. J Biol Chem 268: 19161-19164, 1993.

41. Yu Y, Mu J, Fan Z, Lei G, Yan M, Wang S, Tang C, Wang Z, $\mathrm{Yu} \mathrm{J}$ and Zhang G: Insulin-like growth factor 1 enhances the proliferation and osteogenic differentiation of human periodontal ligament stem cells via ERK and JNK MAPK pathways. Histochem Cell Biol 137: 513-525, 2012.

42. Sun Y, Liu WZ, Liu T, Feng X, Yang N and Zhou HF: Signaling pathway of MAPK/ERK in cell proliferation, differentiation, migration, senescence and apoptosis. J Recept Signal Transduct Res 35: 600-604, 2015.

43. Choi YJ, Lee WS, Lee EG, Sung MS and Yoo WH: Sulforaphane inhibits IL-1 $\beta$-induced proliferation of rheumatoid arthritis synovial fibroblasts and the production of MMPs, COX-2, and PGE2. Inflammation 37: 1496-1503, 2014.

44. Song L, Zhao J, Zhang X, Li H and Zhou Y: Icariin induces osteoblast proliferation, differentiation and mineralization through estrogen receptor-mediated ERK and JNK signal activation. Eur J Pharmacol 714: 15-22, 2013.

45. Luo XH, Guo LJ, Yuan LQ, Xie H, Zhou HD, Wu XP and Liao EY: Adiponectin stimulates human osteoblasts proliferation and differentiation via the MAPK signaling pathway. Exp Cell Res 309: 99-109, 2005.

46. ten Dijke P, Miyazono K and Heldin $\mathrm{CH}$ : Signaling inputs converge on nuclear effectors in TGF-beta signaling. Trends Biochem Sci 25: 64-70, 2000.

47. Rawadi G, Vayssière B, Dunn F, Baron R and Roman-Roman S: BMP-2 controls alkaline phosphatase expression and osteoblast mineralization by a Wnt autocrine loop. J Bone Miner Res 18: 1842-1853, 2003

48. Kong XH, Niu YB, Song XM, Zhao DD, Wang J, Wu XL, Zhang R and Mei QB: Astragaloside II induces osteogenic activities of osteoblasts through the bone morphogenetic protein-2/MAPK and Smad1/5/8 pathways. Int J Mol Med 29: 1090-1098, 2012.

49. Usui T: Pharmaceutical prospects of phytoestrogens. Endocr J 53: 7-20, 2006.

50. Ranasinghe S, Ansumana R, Lamin JM, Bockarie AS, Bangura U, Buanie JA, Stenger DA and Jacobsen KH: Herbs and herbal combinations used to treat suspected malaria in Bo, Sierra Leone. J Ethnopharmacol 166: 200-204, 2015.

51. Tang DZ, Yang F, Yang Z, Huang J, Shi Q, Chen D and Wang YJ: Psoralen stimulates osteoblast differentiation through activation of BMP signaling. Biochem Biophys Res Commun 405: 256-261, 2011. 